\title{
Observing, Performing, and Understanding Actions: Revisiting the Role of Cortical Motor Areas in Processing of Action Words
}

\author{
Shirley-Ann Rueschemeyer ${ }^{1,2}$, Matthias Ekman ${ }^{1}$, Markus van Ackeren ${ }^{2}$, \\ and James Kilner ${ }^{3}$
}

\begin{abstract}
Language content and action/perception have been shown to activate common brain areas in previous neuroimaging studies. However, it is unclear whether overlapping cortical activation reflects a common neural source or adjacent, but distinct, sources. We address this issue by using multivoxel pattern analysis on fMRI data. Specifically, participants were instructed to engage in five tasks: (1) execute hand actions (AE), (2) observe hand actions (AO), (3) observe nonbiological motion (MO), (4) read action verbs, and (5) read nonaction verbs. A classifier was trained to distinguish between data collected from neural motor areas during (1) AE versus MO and (2) AO versus MO. These two algorithms were then used to test for a distinction between data collected during the reading of action versus nonaction
\end{abstract}

\section{INTRODUCTION}

In the past decade, many studies have shown that conceptual information activates perceptual and motor areas of the brain. For example, words denoting actions activate the neural motor system (Rueschemeyer, Rooij, Lindemann, Willems, \& Bekkering, 2010; Postle, McMahon, Ashton, Meredith, \& de Zubicaray, 2008; Rueschemeyer, Brass, \& Friederici, 2007; Hauk, Johnsrude, \& Pulvermueller, 2004), whereas language denoting motion ("the car approaches") activates parts of the visual processing stream responsive to visually perceived motion (Rueschemeyer, Glenberg, Kaschak, Mueller, \& Friederici, 2010; Saygin, McCullough, Alac, \& Emmorey, 2010). In the past decade, converging evidence from behavioral, neuroimaging, and patient data all point consistently to the idea that language comprehension involves sensory-motor areas in a contentspecific manner (reviews by Binder, Desai, Graves, \& Conant, 2009; Aziz-Zadeh \& Damasio, 2008; Zwaan \& Fischer, 2008).

It should be noted that the automaticity and consistency with which lexical forms activate sensory-motor areas remain a topic of open debate. Several studies have demon-

\footnotetext{
${ }^{1}$ Radboud University, Nijmegen, The Netherlands, ${ }^{2}$ University of York, UK, ${ }^{3}$ University College London, UK
}

verbs. The results show that the algorithm trained to distinguish between $\mathrm{AE}$ and $\mathrm{MO}$ distinguishes between word categories using signal recorded from the left parietal cortex and preSMA, but not from ventrolateral premotor cortex. In contrast, the algorithm trained to distinguish between $\mathrm{AO}$ and $\mathrm{MO}$ discriminates between word categories using the activity pattern in the left premotor and left parietal cortex. This shows that the sensitivity of premotor areas to language content is more similar to the process of observing others acting than to acting oneself. Furthermore, those parts of the brain that show comparable neural pattern for action execution and action word comprehension are high-level integrative motor areas rather than low-level motor areas.

strated that embodied language effects are highly sensitive to linguistic and pragmatic context as well as to task demands. For example, words with motor meaning used in idiomatic phrases or nonliteral sentences, which are largely devoid of motor content (e.g., "he kicked the bucket"), have been shown to elicit less or no activation in sensory-motor areas (Schuil, Smits, \& Zwaan, 2013; Van Dam, van Dijk, Bekkering, \& Rueschemeyer, 2012; Raposo, Moss, Stamatakis, \& Tyler, 2009; Rueschemeyer et al., 2007; but see also Boulenger, Hauk, \& Pulvermuller, 2009). Likewise, words with no motor meaning, which are used to imply a request for action (e.g., "it is hot in here" spoken in the context of a closed window), do activate sensory-motor areas reliably (Van Ackeren, Casasanto, Hagoort, Bekkering, \& Rueschemeyer, 2012), suggesting that lexical forms are not necessary to elicit motor activation. Finally, words presented in the context of a motor task are more likely to elicit activation patterns consistent with an embodied framework of words presented in nonmotoric contexts (e.g., Tomasino \& Rumiati, 2013; Papeo, Rumiati, Cecchetto, \& Tomasino, 2012). Thus, the recruitment of sensory-motor areas appears to be a flexible enterprise that is affected by linguistic and pragmatic context as well as task demands.

A wide range of theoretical accounts are offered to explain the link between language and sensory-motor 
processing (for reviews, see Kiefer \& Pulvermueller, 2012; Meteyard, Cuadrado, Bahrami, \& Vigliocco, 2012; Barsalou, 2008). On one side, sensory-motor involvement in language processing is thought to be epiphenomenal (e.g., Mahon \& Caramazza, 2008; Patterson, Nestor, \& Rogers, 2007). Such accounts argue that semantic information is instantiated in an abstract format distinct from modality-specific cortical areas. Any activation of sensorymotor areas during language processing tasks is thought to reflect late mental imagery, morphological, and/ or ortho-phonological statistical properties of lexical items rather than the locus of semantic content (see also De Zubicaray, Arciuli, \& McMahon, 2013; Papeo, PascualLeone, \& Caramazza, 2013). On the other extreme are accounts proposing that semantic information is stored in sensory-motor code (Pulvermueller, 2005; Glenberg \& Kaschak, 2002). This reenactment view proposes that modality-specific activations during language processing are representational in nature. Between the two extremes lie theories proposing that features of semantic content are represented in sensory-motor codes but that abstraction of these features and integration across multiple perceptual and cognitive domains are necessary during language comprehension (e.g., Kiefer \& Pulvermueller, 2012; Barsalou, 2008; Vigliocco, Vinson, Lewis, \& Garrett, 2004). This integrative view proposes that modalityspecific areas reflect general representation of content; however, the temporal and spatial characteristics of modality-specific activations differ for language and action experiences.

In this experiment, we used a pattern classification approach to distinguish between these three accounts (Mur, Bandettini, \& Kriegeskorte, 2009). Whereas previous neuroimaging studies have demonstrated that words with specific content modulate modality-specific brain areas, we aimed to assess whether cortical processes in motor areas share the same neural basis for motor experience and language comprehension. To this end, a classifier was trained to distinguish between neural activity associated with (1) action execution (AE) versus nonbiological motion and (2) action observation (AO) versus observation of nonbiological motion. The classifiers trained to make these two distinctions were then tested on patterns of neural activity elicited by words denoting actions versus words denoting nonbiological motion. If the classifier trained on neural activity elicited by actual action experience can distinguish between activity elicited by the comprehension of different word categories, this bolsters the claim that previously reported results indeed reflect a common neural mechanism for language and action (note that this stands in contrast to the prediction of integration theories). If the classifier fails to distinguish between activity elicited by the different word categories, this will show that the mechanisms underlying action and language processing are not the same (note: in contrast to the prediction of reenactment theories).

\section{METHODS}

\section{Participants}

Twenty-two participants (seven men, $M=22.22$ years, $S D=1.99$ years) took part in this study after giving informed consent. Participants were recruited through the Radboud University participant pool and were reimbursed financially or with course credit for their time. All participants were native speakers of Dutch, had no history of neurological disorder, and had normal or corrected-to-normal eyesight.

\section{Stimuli}

Participants were presented with stimuli in five conditions: $\mathrm{AE}, \mathrm{AO}$, nonbiological motion observation (MO), action words (AW), and nonaction words (NW). Word stimuli were matched across conditions with respect to word length $(t(118)=-1.61, p>.1)$, frequency per million $(t(118)=$ $1.01, p>.1)$, and motion imageability $(t(118)=.05, p>$ .1 ; for means per condition, please see below). For a complete list of the word stimuli used, please see Appendix 1.

- AE: Participants watched a short film clip (2 sec) in which they saw a hand executing a simple intransitive action (e.g., extending and flexing the fingers). After $2 \mathrm{sec}$, the video disappeared completely. Participants then executed the instructed action continuously for $30 \mathrm{sec}$. Onset and offset of the participants movement were marked with a button press. Twelve different hand actions were executed. The AE condition is for all intents and purposes an action imitation condition, but critically, it involves explicit execution of a hand motor act.

- AO: Participants observed an intransitive hand action for 30 sec. In total, 12 video clips showing different hand actions were used.

- MO: Participants observed mechanical toys (i.e., nonbiological agents) in motion. Film clips lasted $30 \mathrm{sec}$. In total, 12 video clips showing three different mechanical toys were used.

- AW: Participants read 10 verbs depicting hand actions (e.g., "to grasp," "to pinch"); each word was presented for $3 \mathrm{sec}$. In total, 60 words were presented (mean length $=7.45, S E=0.19$; mean frequency $=36.57$, $S E=6.24$; mean motion imageability $=0.43, S E=0.02$ ).

- NW: Participants read 10 verbs depicting highly imageable but nonbiological events (e.g., "to snow," "to melt"); each word was presented for $3 \mathrm{sec}$. As in the case of the action verbs, 60 words were presented in total (mean length $=7.88, S E=0.19$; mean frequency $=$ $24, S E=10.8$; mean motion imageability $=0.428, S E=$ 0.03 ; for a complete list of words, please see Appendix 1).

\section{Task}

Participants were asked to watch the stimuli carefully. Following the presentation of five experimental blocks 
(e.g., one instance of each condition), participants were shown three stimuli (e.g., words or videos) and asked to indicate whether each stimulus had appeared in the previous set of stimuli. Participants responded via button press. The purpose of the task was (1) to ensure that participants attended to stimuli and (2) to provide an overt hand movement temporally independent from any experimental stimulus to use as a hand action localizer.

\section{Stimulus Presentation}

Stimuli were presented in 12 chunks, each consisting of five 30-sec blocks separated by a 6-sec interblock interval (see Figure 1). Chunks were made temporally independent from one another by including a 20-sec interchunk interval. Each block contained stimuli from one of each of the five conditions ( $\mathrm{AE}, \mathrm{AO}, \mathrm{MO}, \mathrm{AW}, \mathrm{NW}$ ). The order of blocks within each chunk was pseudorandomized, so that each chunk had a unique order of block presentation. Following each chunk, participants were presented with three stimuli (e.g., video clips, word stimuli) and asked to indicate whether the stimuli were included in the preceding chunk.

\section{Data Acquisition}

MRI data acquisition was performed on a Siemens Magnetom Trio scanner (Siemens Medical System, Erlangen, Germany) with a magnetic field strength of $3 \mathrm{~T}$. The functional scans were acquired using a multiecho gradient pulse sequence (repetition time $=2390 \mathrm{msec}$; echo time $=9.4$, $21.17,32.94,44.71$, and $56.48 \mathrm{msec}$; flip angle $=90^{\circ}$ ). Each volume consisted of 31 transversal slices with a thickness of $3 \mathrm{~mm}$. The voxel resolution was $3.5 \mathrm{~mm} \times 3.5 \mathrm{~mm} \times$ $3.5 \mathrm{~mm}$. After the collection of functional data, a structural scan was performed for each individual participant. The image was a T1-weighted 3-D magnetization prepared rapid gradient echo sequence comprising 192 sagittal slices (repetition time $=2300 \mathrm{msec}$, echo time $=3.03 \mathrm{msec}$, slice thickness $=1 \mathrm{~mm}$ ).

\section{Data Analysis}

\section{fMRI Preprocessing}

SPM8 was used to initially transform DICOM images into NIFTI images for further processing. Subsequently, six movement parameters (three translations and three rotations) were extracted from the first echo of each volume and subsequently used to correct for small head movements in all five echoes of each volume. All five echoes were then combined into a single volume using a weighted average (Poser, Versluis, Hoogduin, \& Norris, 2006). Further preprocessing and data analysis were carried out using FMRIB's Software Library 4.1.9 (Smith, Jenkinson, Woolrich, Beckman, \& Behrens, 2004). A high-pass temporal filter using a 100-sec cutoff was applied, and images were normalized into a 2-mm standard stereotaxic space (Montreal Neurological Institute). No spatial smoothing was performed to preserve local voxel information.

\section{Functional Localizer}

Motor areas were defined using a general linear model and carried out using fMRI Expert Analysis Tool 5.92. A canonical gamma function was used to model the BOLD response. The model contained six regressors, the button press plus five task conditions. The contrast was calculated as button press versus baseline. Statistical maps were computed using FMRIB's Local Analysis of Mixed Effects stage 1 (Woolrich, Behrens, Beckmann, Jenkinson, \& Smith, 2004) and thresholded with a $z$ value of 2.56 and a corrected cluster significance threshold of $p<.05$ (Worsley, 2001).

\section{Multivoxel Pattern Classification}

Two types of pattern classification analyses were performed. First, the classifier was trained and tested on the same conditions, namely, (1) AE versus MO and (2) AO versus MO. This ensures that the classifier successfully learned to distinguish between task conditions. ROIs were only included in the second level of analysis if the classifier was successful in learning to distinguish between the initial task conditions. In ROIs in which the first level of pattern classification was successful, the trained classifiers
Figure 1. Stimulus presentation. Stimuli from the five experimental conditions (AE, AO, MO, AW, NW) were presented in random order in blocks of $30 \mathrm{sec}$ each. Between each block of stimuli, a 6-sec interblock interval (IBI) was inserted. At the end of each chunk of five stimulus blocks, a short question block was presented, which gauged

participant's attention and required participants to make an overt button press. Between chunks, a 20-sec interchunk interval (ICI) was inserted to ensure the temporal independence of chunks.

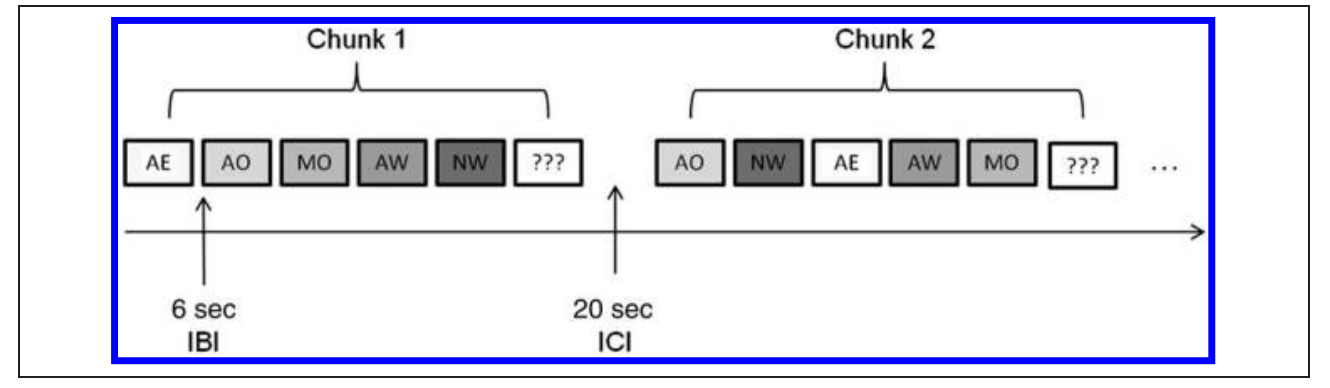


Figure 2. (Top) Areas identified by the functional localizer (i.e., simple button press; cluster corrected threshold, $p<.05)$. (Bottom) ROIs used for classification analysis (sphere with 9-mm radius surround peak activations in areas seen on top. $\mathrm{L}=$ left; $\mathrm{R}=$ right.

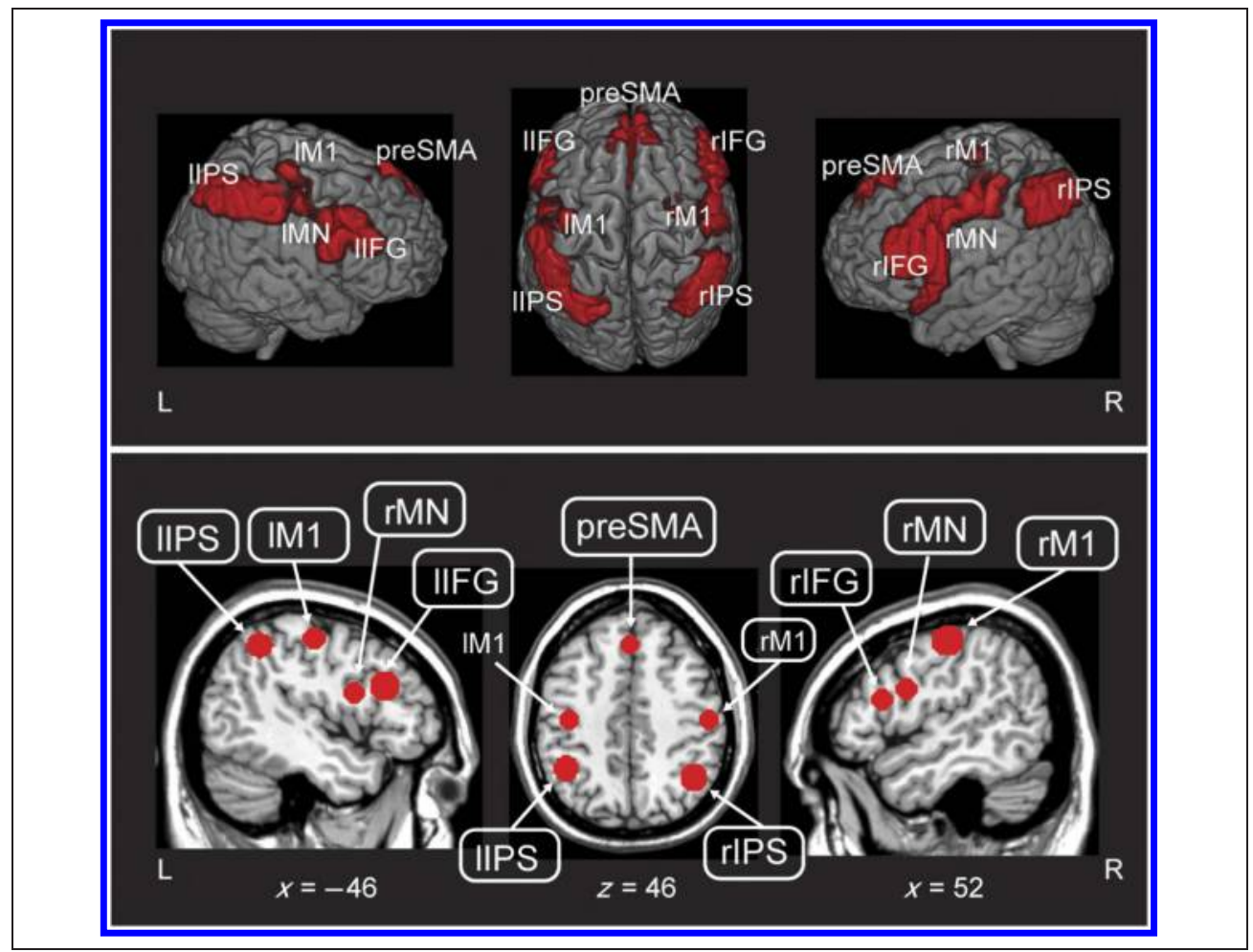

were used to test between the reading of action versus nonaction verbs (AW vs. NW). Importantly, this was done without any further training of the initial classifier.

Each task condition was modeled with a general linear model containing a separate regressor for every chunk. Note that the chunk for AE condition was the time between button presses, during which participants repeatedly executed the action they had been shown in the 2 -sec video clip. Resulting beta estimates $(12 \times 5$ per participant) were $z$ scored to a mean of 0 and to a standard deviation of 1 . In each fold, a linear support vector machine $(C=1)$ was trained on the extracted voxel pattern for all but one participant. The remaining participant was used as an independent test set. This procedure (leave-oneparticipant-out cross-validation with $n=22$ folds; Clithero, Smith, Carter, \& Huettel, 2011) was repeated until every participant was used in the test set once. The classification analysis was performed separately for seven ROIs identified by the functional localizer and two taken from the literature, which correspond to the putative location of mirror neurons in the lateral pFC (Oosterhof, Tipper, \& Downing, 2012; Kilner, Neal, Wiskopf, Friston, \& Frith, 2009). Note that the classification tests a common spatial pattern across participants as opposed to between trials.

A statistical test of the classification accuracy was performed using a nonparametric permutation analysis (Nichols \& Holmes, 2002). To this end, we repeated each classification 10.000 times with shuffled task labels. The $p$ value was calculated as the amount of times the permuted classification reached an accuracy level higher or equal to the original classification accuracy without permu- tation, divided by the total number of permutations. All classification analyses were performed using the PyMVPA software package (Hanke et al., 2009).

\section{RESULTS}

\section{Functional Localizer}

The results of the functional localizer show brain areas that were activated when participants performed an action with their right hand (i.e., pushed a button). Importantly, this hand action was not performed in conjunction with any of the critical experimental conditions; thus, the data from this condition are temporally independent from the experimental data in this experiment. The results of the functional localizer show activation in conjunction with button presses in seven large regions. These included bilateral inferior frontal gyrus (part of the ventral premotor cortex; e.g., Binkofski \& Buccino, 2006), bilateral inferior parietal cortex, bilateral primary motor cortex (M1), and the pre-SMAs (preSMAs). In addition, we included two additional ROIs in the bilateral ventral premotor cortex, which target specific areas in the premotor cortex that have been described previously as potential sites for mirror neurons in humans (Oosterhof et al., 2012; Kilner et al., 2009). We created a spherical ROI with radius $=9 \mathrm{~mm}$ (358 voxels) around the peak coordinates of the functional localizer map (see Figure 2). This results in nine, equally sized ROIs that were used for all subsequent analyses: (1) left inferior frontal gyrus (IIFG), (2) right IFG (rIFG), (3) the preSMA, (4) left intraparietal sulcus 
Table 1. Classifier Performance Rates and Spatial Information for ROIs

\begin{tabular}{|c|c|c|c|c|c|}
\hline \multirow[b]{3}{*}{$R O I$} & \multirow{3}{*}{$\frac{\frac{\text { Coordinates }}{\text { Spherical ROI Centers }}}{x, y, z}$} & \multicolumn{4}{|c|}{ Classification Performance } \\
\hline & & \multicolumn{2}{|c|}{ Trained on $A E$ versus $M O$} & \multicolumn{2}{|c|}{ Trained on AO versus $M O$} \\
\hline & & Test: AE versus $M O$ & Test: $A W$ versus $N W$ & Test: $A O$ versus $M O$ & Test: AW versus $N W$ \\
\hline IIFG & $-46,24,24$ & $67.50 * *$ & 54.54 & $85.00 * * *$ & $70.45 * * *$ \\
\hline rIFG & $46,20,18$ & $70.00 * *$ & 50.12 & $67.50 * *$ & $65.00 * *$ \\
\hline preSMA & $0,32,40$ & $77.50 * * *$ & $75.00 * * *$ & $70.00 * *$ & 50.00 \\
\hline IIPS & $-42,-50,48$ & $70.00 * * *$ & $62.50 * *$ & $80.84 * * *$ & $67.5^{* * *}$ \\
\hline rIPS & $42,-56,46$ & $62.50 * *$ & $72.50 * * *$ & $75.00 * *$ & 52.50 \\
\hline lM1 & $-40,-18,52$ & 50.12 & - & 53.64 & - \\
\hline rM1 & $52,-18,52$ & 49.95 & - & 55.09 & - \\
\hline $\mathrm{IMN}$ & $-53,6,21$ & 50.12 & - & 47.87 & - \\
\hline rMN & $57,6,24$ & 55.09 & - & 52.91 & - \\
\hline
\end{tabular}

Information about the center of each spherical ROI (Montreal Neurological Institute coordinates, size $=358$ voxels) is provided in the second column. Performance rates for classifiers are provided for each ROI in the final four columns. The columns shaded in gray show the performance rates when the classifier was trained on $\mathrm{AE}$ versus $\mathrm{MO}$ and then tested on (1) AE versus $\mathrm{MO}$ and (2) AW versus NW. The final two columns show the performance rates when the classifier was trained on $\mathrm{AO}$ versus $\mathrm{MO}$ and then tested on (1) AO versus MO and (2) AW vs. NW. Performance rates are shown for each ROI individually. Asterisks represent significance level.

$* p<.05$.

$* * p<.01$.

$* * * p<.005$

(IIPS), (5) right IPS (rIPS), (6) left M1 (lM1), (7) right M1 (rM1), (8) left ventrolateral premotor cortex (lMN), and (9) right $\mathrm{MN}(\mathrm{rMN})$.

\section{Pattern Classification}

Using the pattern of activation identified in each of the nine ROIs, a classifier was trained to distinguish between neural activity associated with (1) AE in contrast to nonbiological motion (AE vs. MO) and (2) AO in contrast to observation of nonbiological motion ( $\mathrm{AO}$ vs. MO). If the classifier was able to reliably distinguish between these categories (i.e., performance significantly above chance), it was subsequently tested on patterns of neural activity elicited by words denoting actions (e.g., "to grasp," "to pinch") in contrast to words denoting nonbiological motion (e.g., "to flow," "to melt"; AW vs. NW).

\section{$A E$ versus $M O$}

In five of nine ROIs, the classifier trained to distinguish between $\mathrm{AE}$ and $\mathrm{MO}$ was able to distinguish between a test set of $\mathrm{AE}$ and $\mathrm{MO}$ stimuli, which were not included in the training session (all $p s<.001$; see Table 1 for exact performance rates and $p$ values). This shows that the classifier successfully learned to discriminate between $\mathrm{AE}$ and MO. The signal from these five ROIs was thus reliable for training and testing between action conditions (i.e., train $\mathrm{AE}$ vs. $\mathrm{MO}$, test $\mathrm{AE}$ vs. MO) and can therefore be used for training and then testing across word conditions (i.e., train AE vs. MO, test AW vs. NW). These ROIs were the bilateral IFG, the bilateral IPS, and the preSMA. The additional four ROIs were not tested further.

Without further training, the AE-versus-MO classifier was applied to distinguish between the word categories (AW vs. NW) in the five successful ROIs. The classifier successfully predicted word categories using information from the bilateral IPS and preSMA, but not using information from IFG (see Table 1, Figure 3).



Figure 3. Classification accuracy for the prediction of reading AW versus NW. Accuracy for algorithm trained on $\mathrm{AE}$ versus $\mathrm{MO}$ is shown in black; accuracy for the algorithm trained on $\mathrm{AO}$ versus MO is shown in gray. 


\section{AO versus $M O$}

The classifier trained to distinguish between $\mathrm{AO}$ and $\mathrm{MO}$ showed significant classification accuracy in five of the nine ROIs (all $p s<.001$; see Table 1). As explained above, this indicates that the pattern extracted from these five ROIs is reliable for training and testing between action conditions (i.e., train $\mathrm{AO}$ vs. $\mathrm{MO}$, test $\mathrm{AO}$ vs. $\mathrm{MO}$ ) and is therefore viable for use in training and testing across word conditions (i.e., train $\mathrm{AO}$ vs. $\mathrm{MO}$, test $\mathrm{AW}$ vs. $\mathrm{NW})$. Therefore, the AO-versus-MO classifier was used in these five ROIs to distinguish between AW and NW. Categorization was successful based on signal from IIPS and IIFG, but not using the signal from the preSMA nor either of the right hemisphere ROIs.

\section{DISCUSSION}

In the current study, we used a pattern classification method to investigate the spatial similarity of the signal elicited in motor areas by $\mathrm{AE}, \mathrm{AO}$, and the comprehension of AW. Our results show (1) that the pattern of activation elicited by AE and AW was comparable within the preSMA and bilateral IPS, but not within bilateral ventrolateral premotor cortex (vlPMC). Second, the pattern of activation elicited by $\mathrm{AO}$ and $\mathrm{AW}$ was comparable within IIFG and IIPS. The results of this study make two important contributions: (1) activation in the lateral frontoparietal motor areas, often reported previously for the comprehension of AW, is shown to be inconsistent with the pattern of activation elicited by the execution of actual motor movements. Second, the pattern of activation observed in lateral frontoparietal motor areas in conjunction with $\mathrm{AW}$ is consistent with the pattern of activation observed during AO. The implications of these findings are discussed further below.

\section{Lateral PMC}

The central claim of many embodied theories of language is that modality-specific brain areas are involved in the representation of conceptual information because words initiate a reenactment of actual experience. For example, action verbs such as "grasp" or "kick" activate the respective neural motor areas involved in actually planning and executing grasping or kicking actions (e.g., Pulvermueller, 2005). One popular proposal has been that, during development, the common co-occurrence of performing a given action and hearing the word denoting the action causes word form and the neural correlates of acting to become connected (Hebbian learning; Pulvermueller, 1999, 2005). Thus, premotor and even primary motor areas are assumed to play a crucial role in representing meaning of action verbs and concepts. The bulk of evidence in favor of this perspective shows selective activation of neural substrate close to or within primary motor and premotor areas (e.g., Aziz-Zadeh, Wilson,
Rizzolatti, \& Iacoboni, 2006; Tettamanti et al., 2005; Hauk et al., 2004).

The current data show that the signal elicited in the ventral PMC by action verbs is not spatially comparable with that elicited by AE. On the other hand, the spatial parameter of activation within ventral PMC during the comprehension of AW is very similar to what is seen during AO. Intuitively, this finding is reasonable: Language stimuli may evoke an internal form of observation as we follow the verbal description of an unfolding event that is fundamentally different to the processes involved in preparing to act or imagining one's own movements. Although these results indicate that overlapping activation reported previously for $\mathrm{AE}$ and word comprehension (e.g., Rueschemeyer et al., 2007; Hauk et al., 2004) probably does not reflect a common neural substrate, shared activation reported in conjunction with $\mathrm{AO}$ and word comprehension indeed result from common neural resources (e.g., Aziz-Zadeh et al., 2006). Interestingly, a previous study has shown that action word comprehension activates neural resources distinct from those engaged by instructed motor imagery (Willems, Toni, Hagoort, \& Casasanto, 2009); thus, the internal observation of actions suggested here contrasts with imagining what it would be like to perform an action oneself and is more comparable with the process of visually perceiving another acting.

It is worth noting that the involvement of the cortical motor areas in processing lexical-semantic meaning has been shown to be influenced by task demands (Tomasino \& Rumiati, 2013; Papeo et al., 2012; Van Dam et al., 2012). Specifically, it has been argued that words elicit more reliable activation with cortical motor areas in language and situational contexts that highlight motor acts (e.g., performing mental rotation, thinking about actions vs. forms, etc.). In the current study, participants were arguably motivated to reflect on actions (e.g., they acted out and observed hand actions within each experimental chunk as well as processing word stimuli). Thus, based on previous literature, the current paradigm is one in which the link between AW and cortical motor areas should be strong. Nevertheless, under these optimized conditions, our results show that the pattern of activation across multiple voxels in the cortical motor network is different for the processing of AW and the execution of hand actions.

\section{Medial PMC and Parietal Cortex}

In this study, $\mathrm{AE}$ and action word comprehension do elicit similar patterns of activation in cortical regions outside lateral PMC. Good correspondence between the pattern of activation elicited by actions and words was observed in medial PMC (preSMA) and bilateral IPS. Both the preSMA and IPS are known to play key roles in the planning and execution of actions (e.g., Fogassi \& Luppino, 2005; Picard \& Strick, 2001), but both are involved in high-level integrative forms of action planning (e.g., adapting actions to a given context), rather than servicing the 
control of individual muscles. This suggests that the parts of the network that are activated in a comparable manner across $\mathrm{AE}$ and language comprehension are highlevel abstractions of motor movements and not low-level residual traces of actual movements.

To summarize the results thus far, ventrolateral PMC is not engaged in the same manner during $\mathrm{AE}$ and action word comprehension. On the one hand, this is unsurprising, as participants in the word condition are not engaged in any action, and brain activation should hopefully reflect that nontrivial distinction. On the other hand, this finding stands in contrast to the interpretation offered by the numerous studies, which have reported consistent overlapping activation in lateral premotor sites for $\mathrm{AE}$ and action word comprehension. The results of the current study suggest that the results of previous studies do not reflect a common neural mechanism, but rather either spatially or temporally different processes in nearby neural tissue. In contrast, activation in higher-level integrative motor areas (i.e., preSMA and IPS) is common to action word content and $\mathrm{AE}$.

There are three conclusions that can be drawn from the current experiment. First, brain areas showing comparable activation across action and language processing are highlevel multimodal areas (e.g., preSMA, IPS). The areas in question are undoubtedly also crucial components of the neural motor system, but they are not domain specific in the same manner that M1 is. Thus, action and language content share common representation, but the code in which lexical-semantic information is stored cannot be described as motor based. This finding stands in contrast to strongly embodied theories but is in general correspondence with more moderate and weakly embodied perspectives.

Second, the function of high-level multimodal areas is surprisingly consistent across participants. We trained our classifier to distinguish between $\mathrm{AE}$ and $\mathrm{MO}$ on the basis of signal generated from one participant (or multiple participants) but tested its performance on the signal generated in another participant. Therefore, we show not only that patterns of brain activation are common across cognitive tasks but also that there is a high degree of commonality across participants in the functional profile of high-level cognitive areas (preSMA, IPS).

Third, we contribute to the accumulating evidence suggesting different functional roles for IIFG/vlPMC engagement during $\mathrm{AE}$ and $\mathrm{AO}$. Specifically, although evidence for the existence of small populations of neurons sensitive to both AE and AO exists (e.g., Kilner et al., 2009; for a review, see Rizzolatti \& Craighero, 2004), the vast majority of neurons within PMC has been shown to exhibit different patterns of activation during execution and observation (e.g., Press, Weiskopf, \& Kilner, 2012; Lingnau, Gesierich, \& Caramazza, 2009). There are several points that make a distinction between execution and observation plausible. First, although it is likely that the posterior PMC is involved in forming predictions about the consequences of actions during both AE and AO (for a review, see Kilner, 2011), the predicted consequences of acting and observing are often quite different (see, e.g., Newman-Norlund, van Schie, van Zuijlen, \& Bekkering, 2007). In line with this, Oosterhof et al. (2012) demonstrate that the pattern of activation in the posterior PMC elicited by AE and observation is similar if actions are presented from the first-person perspective but that this similarity does not hold if actions are presented from the third-person perspective. In the current study, we show that the pattern of activation in the IIFG/vPMC is similar for $\mathrm{AO}$ and word comprehension, but not for $\mathrm{AE}$ and lexical-semantic processing. We suggest above that words generate internal simulations of actions that are more similar to watching others act than to acting oneself. Thus, we show that action-word content does activate the IIFG/vPMC (i.e., does draw on resources of neural motor areas), but it does so in a manner akin to watching others act rather than to acting oneself.

\section{Conclusion}

In the current study, we used multivoxel pattern analysis to investigate whether overlapping cortical activation reported previously for $\mathrm{AE}$ and action-word comprehension reflects a common neural source or adjacent, but distinct, sources. The results demonstrate that overlapping activation in high-level multimodal areas (e.g., preSMA, IPS) reflects activation of a common source for $\mathrm{AE}$ and word comprehension. In contrast, activation in modality-specific areas (e.g., vlPMC) reflects activation of a common source for $\mathrm{AO}$ and word comprehension, but not for AE. The results of this study demonstrate that lexical-semantic meaning is derived from features that make use of neural substrate also involved in executing and observing actions in the real world but that the code in which action features are stored in the brain cannot be equated with motor content.

\section{APPENDIX 1: DUTCH WORDS IN THE TWO-WORD CONDITIONS AND THEIR ENGLISH TRANSLATION EQUIVALENTS}

\begin{tabular}{ll}
\hline Original Dutch Stimuli & English Translation Equivalents \\
\hline Action Words & \\
aaien & stroke/caress \\
aansteken & use a lighter \\
aftasten & examine (with the hands) \\
bedekken & cover (with hands) \\
betalen & pay \\
bonken & bump \\
borstelen & brush \\
\hline
\end{tabular}


APPENDIX 1 (continued)

\begin{tabular}{|c|c|}
\hline Original Dutch Stimuli & English Translation Equivalents \\
\hline \multicolumn{2}{|l|}{ Action Words } \\
\hline breken & break \\
\hline buigen & bend/fold \\
\hline deppen & blot/dab \\
\hline dobbelen & throw a die \\
\hline duwen & push \\
\hline epileren & tweeze \\
\hline fladderen & flutter \\
\hline fotograferen & take a photograph \\
\hline gooien & throw \\
\hline grabbelen & grabble \\
\hline grijpen & grasp \\
\hline hameren & hammer \\
\hline kerven & carve \\
\hline knijpen & pinch \\
\hline knutselen & fiddle \\
\hline naaien & sew \\
\hline noteren & write down \\
\hline openen & open \\
\hline ophangen & hang up \\
\hline opnemen & take/pick up \\
\hline optillen & lift \\
\hline peuteren & pick \\
\hline pinnen & pin \\
\hline plukken & pluck \\
\hline poetsen & clean \\
\hline prakken & mash \\
\hline prikken & prick \\
\hline puzzelen & do jigsaw puzzles \\
\hline reiken & hand over \\
\hline salueren & salute \\
\hline scheren & shave \\
\hline scheuren & tear \\
\hline schieten & shoot \\
\hline schilderen & paint \\
\hline schrapen & scratch \\
\hline schroeven & screw \\
\hline smeren & smear \\
\hline
\end{tabular}

APPENDIX 1 (continued)

Original Dutch Stimuli

English Translation Equivalents

Action Words

$\begin{array}{ll}\text { smijten } & \text { throw } \\ \text { snijden } & \text { cut } \\ \text { steken } & \text { prick } \\ \text { stompen } & \text { punch } \\ \text { stoten } & \text { push } \\ \text { strelen } & \text { caress } \\ \text { strijken } & \text { iron } \\ \text { strooien } & \text { strew } \\ \text { tekenen } & \text { draw } \\ \text { uitgummen } & \text { erase } \\ \text { verkreukelen } & \text { crease } \\ \text { verspreiden } & \text { spread } \\ \text { verven } & \text { paint } \\ \text { wapperen } & \text { wave } \\ \text { werpen } & \text { throw } \\ \text { wrijven } & \text { rub }\end{array}$

Non-action Words

aanspoelen wash ashore

barsten burst

bestuiven pollinate

bevriezen freeze

blaken scorch

blikkeren flicker

bliksemen blaze

blinken glitter

bloezen droop

blubberen blubber

bollen bulge

detoneren detonate

dooien melt

drogen dry

druppelen drip

fonkelen sparkle

glippen slide

gloeien glow

golven move in waves 


\section{APPENDIX 1 (continued)}

\begin{tabular}{|c|c|}
\hline Original Dutch Stimuli & English Translation Equivalents \\
\hline \multicolumn{2}{|l|}{ Non-action Words } \\
\hline kletteren & clang \\
\hline lekken & leak \\
\hline lubberen & bulge out \\
\hline miezeren & rain \\
\hline misten & fog up \\
\hline ontkiemen & germinate \\
\hline ontladen & explode \\
\hline opladen & load \\
\hline opzwellen & bulge \\
\hline overspoelen & flood \\
\hline ploffen & thud \\
\hline plonzen & splash \\
\hline rijpen & ripen \\
\hline roesten & get rusty \\
\hline roteren & rotate \\
\hline schijnen & shine \\
\hline sidderen & tremble \\
\hline slieren & slither \\
\hline sneeuwen & snow \\
\hline spatten & splash \\
\hline splijten & split \\
\hline splinteren & splinter (v) \\
\hline stijgen & sliver \\
\hline stomen & steam \\
\hline storten & fall \\
\hline uitbarsten & erupt \\
\hline uitdrogen & dry \\
\hline verzachten & drain \\
\hline vallen & fall \\
\hline verbrokkelen & crumble \\
\hline verdampen & evaporate \\
\hline verdikken & thicken \\
\hline vergaan & perish \\
\hline vergroten & enlarge \\
\hline verkolen & char \\
\hline verlichten & light up \\
\hline verzachten & attenuate \\
\hline
\end{tabular}

APPENDIX 1 (continued)

\begin{tabular}{lc}
\hline Original Dutch Stimuli & English Translation Equivalents \\
\hline Non-action Words & \\
waaien & blow (wind) \\
wegebben & fade away \\
zinken & sink \\
zwellen & swell up \\
\hline
\end{tabular}

\section{Acknowledgments}

The present study was supported by a VENI grant (016-094-053) to S.-A.R. from the Dutch Organization for Scientific Research (NWO).

Reprint requests should be sent to Shirley-Ann Rueschemeyer, Department of Psychology, University of York, York, YO10 5DD, UK, or via e-mail: shirley-ann.rueschemeyer@york.ac.uk.

\section{REFERENCES}

Aziz-Zadeh, L., \& Damasio, A. (2008). Embodied semantics for actions: Findings from functional brain imaging. Iournal of Physiology-Paris, 102, 35-39.

Aziz-Zadeh, L., Wilson, S., Rizzolatti, G., \& Iacoboni, M. (2006). Congruent embodied representations for visually presented actions and linguistic phrases describing actions. Current Biologv, 16, 1818-1823.

Barsalou, L. (2008). Grounded cognition. Annual Review of Psvchology, 59, 617-645.

Binder, J. R., Desai, R. H., Graves, W. W., \& Conant, L. L. (2009). Where is the semantic system? A critical review and meta-analysis of 120 functional neuroimaging studies. Cerebral Cortex, 19, 2767-2797.

Binkofski, F., \& Buccino, G. (2006). The role of ventral premotor cortex in action execution and action understanding. Journal of Phvsiologv-Paris, 99, 396-405.

Boulenger, V., Hauk, O., \& Pulvermuller, F. (2009). Grasping ideas with the motor system: Semantic somatotopy in idiom comprehension. Cerebral Cortex, 19, 1905-1914.

Clithero, J. A., Smith, D. V., Carter, R. M., \& Huettel, S. A. (2011). Within- and cross-participant classifiers reveal different neural coding of information. Neuroimage, 56, 699-708.

De Zubicaray, G., Arciuli, J., \& McMahon, K. (2013). Putting and end to the motor cortex representations of action words. Journal of Cognitive Neuroscience, 25, 1957-1974.

Fogassi, L., \& Luppino, G. (2005). Motor functions of the parietal lobe. Current Opinion in Neurobiology, 15, 626-631.

Glenberg, A., \& Kaschak, M. (2002). Grounding language in action. Psychonomic Bulletin \& Review, 9, 558-565.

Hanke, M., Halchenko, Y. O., Sederberg, P. B., Hanson, S. J., Haxby, J. V., \& Pollmann, S. (2009). PyMVPA: A python toolbox for multivariate pattern analysis of fMRI data. Neuroinformatics, 7, 37-53.

Hauk, O., Johnsrude, I., \& Pulvermueller, F. (2004). Somatotopic representation of action words in human motor and premotor cortex. Neuron, 41, 301-307.

Kiefer, M., \& Pulvermueller, F. (2012). Conceptual representations in mind and brain: Theoretical developments, current evidence and future directions. Cortex, 48, 805-825. 
Kilner, J. (2011). More than one pathway to action understanding. Trends in Cognitive Sciences, 15, 352-357.

Kilner, J., Neal, A., Wiskopf, N., Friston, K. J., \& Frith, C. D. (2009). Evidence of mirror neurons in human inferior frontal gyrus. Journal of Neuroscience, 29, 10153-10159.

Lingnau, A., Gesierich, B., \& Caramazza, A. (2009). Asymmetric fMRI adaptation reveals no evidence for mirror neurons in humans. Proceedings of the National Academy of Sciences, U.S.A., 106, 9925-9930.

Mahon, B. Z., \& Caramazza, A. (2008). A critical look at the embodied cognition hypothesis and a new proposal for grounding conceptual content. Journal of Physiology-Paris, 102, 59-70.

Meteyard, L., Cuadrado, S. R., Bahrami, B., \& Vigliocco, G. (2012). Coming of age: A review of embodiment and neuroscience of semantics. Cortex, 48, 1-17.

Mur, M., Bandettini, P. A., \& Kriegeskorte, N. (2009). Revealing representational content with pattern-information fMRI-An introductory guide. Social Cognitive and Affective Neuroscience, 4, 101-109.

Newman-Norlund, R., van Schie, H., van Zuijlen, A., \& Bekkering, H. (2007). The mirror neuron system is more active during complementary compared with imitative action. Nature Neuroscience, 10, 817-818.

Nichols, T. E., \& Holmes, A. P. (2002). Nonparametric permutation tests for functional neuroimaging: A primer with examples. Human Brain Mapping, 15, 1-25.

Oosterhof, N., Tipper, S., \& Downing, P. (2012). Viewpoint (in)dependence of action representations: An MVPA study. Journal of Cognitive Neuroscience, 24, 975-989.

Papeo, L., Pascual-Leone, A., \& Caramazza, A. (2013). Disrupting the brain to validate hypotheses on the neurobiology of language. Frontiers in Human Neuroscience, 7, 1-8.

Papeo, L., Rumiati, R., Cecchetto, C., \& Tomasino, B. (2012). On-line changing of thinking about words: The effect of cognitive context on neural responses to verb reading. Journal of Cognitive Neuroscience, 24, 2348-2362.

Patterson, K., Nestor, P., \& Rogers, T. (2007). Where do you know what you know? The representation of semantic knowledge in the human brain. Nature Reviews Neuroscience, 8, 976-987.

Picard, N., \& Strick, P. (2001). Imaging the premotor areas. Current Opinion in Neurobiology, 11, 663-672.

Poser, B., Versluis, M., Hoogduin, J., \& Norris, D. (2006). BOLD contrast sensitivity enhancement and artifact reduction with multiecho EPI: Parallel-acquired inhomogeneity-desensitized fMRI. Magnetic Resonance in Medicine, 55, 1227-1235.

Postle, N., McMahon, K., Ashton, R., Meredith, M., \& de Zubicaray, G. I. (2008). Action word meaning representations in cytoarchitectonically defined primary and premotor cortices. Neuroimage, 43, 634-644.

Press, C., Weiskopf, N., \& Kilner, J. (2012). Dissociable roles of human inferior frontal gyrus during action execution and observation. Neuroimage, 60, 1671-1677.

Pulvermueller, F. (1999). Words in the brain's language. Behavioral and Brain Sciences, 22, 253-336.

Pulvermueller, F. (2005). Brain mechanisms linking language and action. Nature Reviews Neuroscience, 6, 576-582.

Raposo, A., Moss, H. E., Stamatakis, E. A., \& Tyler, L. K. (2009). Modulation of motor and premotor cortices by actions, action words and action sentences. Neuropsychologia, 47, 388-396.
Rizzolatti, G., \& Craighero, L. (2004). The mirror-neuron system. Annual Review of Neuroscience, 27, 169-192.

Rueschemeyer, S.-A., Brass, M., \& Friederici, A. D. (2007). Comprehending prehending: Neural correlates of processing verbs with motor stems. Journal of Cognitive Neuroscience, 19, 855-865.

Rueschemeyer, S.-A., Glenberg, A., Kaschak, M., Mueller, K., \& Friederici, A. D. (2010). Listening to sentences describing visual motion activates MT/V5. Frontiers in Cognition, 1, $1-11$.

Rueschemeyer, S.-A., Rooij, D., Lindemann, O., Willems, R., \& Bekkering, H. (2010). The function of words: Distinct neural correlates for words denoting differently manipulable objects. Journal of Cognitive Neuroscience, 22, 1844-1851.

Saygin, A. P., McCullough, S., Alac, M., \& Emmorey, K. (2010). Modulation of BOLD response in motion-sensitive lateral temporal cortex by real and fictive motion sentences. Journal of Cognitive Neuroscience, 22, 2480-2490.

Schuil, K., Smits, M., \& Zwaan, R. (2013). Sentential context modulates the involvement of the motor cortex in action language processing: An fMRI study. Frontiers in Human Neuroscience, 7, 1-13.

Smith, S., Jenkinson, M., Woolrich, M., Beckman, C., \& Behrens, T. (2004). Advances in functional and structural MR image and analysis and implementation as FSL. Neuroimage, 23, S208-S219.

Tettamanti, M., Buccino, G., Saccuman, M. C., Gallese, V., Danna, M., Scifo, P., et al. (2005). Listening to action-related sentences activates fronto-parietal motor circuits. Journal of Cognitive Neuroscience, 17, 273-281.

Tomasino, B., \& Rumiati, R. (2013). At the mercy of strategies: The role of motor representations in language understanding. Frontiers in Psychology, 4, 1-13.

Van Ackeren, M., Casasanto, D., Hagoort, P., Bekkering, H., \& Rueschemeyer, S.-A. (2012). Pragmatics in action: Indirect requests engage theory of mind areas and the cortical motor network. Journal of Cognitive Neuroscience, 24, 2237-2247.

Van Dam, W. O., van Dijk, M., Bekkering, H., \& Rueschemeyer, S.-A. (2012). Flexibility in embodied lexical-semantic representations. Human Brain Mapping, 33, 2322-2333.

Vigliocco, G., Vinson, D. P., Lewis, W., \& Garrett, M. (2004). Representing the meanings of object and action words: The featural and unitary semantic space hypothesis. Cognitive Psychology, 48, 422-448.

Willems, R., Toni, I., Hagoort, P., \& Casasanto, D. (2009). Neural dissociations between action verb understanding and motor imagery. Journal of Cognitive Neuroscience, 22, 2387-2400.

Woolrich, M. W., Behrens, T., Beckmann, C., Jenkinson, M., \& Smith, S. (2004). Multi-level linear modelling for fMRI group analysis using Bayesian inference. Neuroimage, $21,1732-1747$.

Worsley, K. (2001). Statistical analysis of activation images. In P. Jezzard, P. Matthews, \& S. Smith (Eds.), Functional MRI: An introduction to methods (Chap. 14, pp. 251-270). Oxford, UK: Oxford University Press.

Zwaan, R., \& Fischer, M. (2008). Embodied language: A review of the role of the motor system in language comprehension. Quarterly Journal of Experimental Psychology, 61, 825-850. 